\title{
Phase Behavior of TPGS-PEG400/1450 Systems and Their Application to Liquid Formulation: A Formulation Platform Approach
}

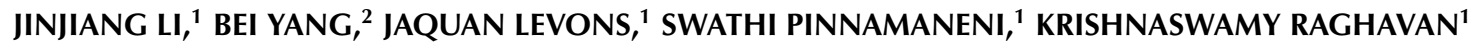 \\ ${ }^{1}$ Drug Product Science \& Technology, Bristol-Myers Squibb Company, New Brunswick, New Jersey 08903 \\ ${ }^{2}$ School of Pharmacy, University of Michigan, Ann Arbor, Michigan 48109
}

Received 9 March 2010; revised 3 February 2011; accepted 18 May 2011

Published online 8 June 2011 in Wiley Online Library (wileyonlinelibrary.com). DOI 10.1002/jps.22659

\begin{abstract}
Vitamin E D-alpha-tocopheryl polyethylene glycol succinate (TPGS) and polyethylene glycol are common excipients used in both preclinical and commercial formulations. In this paper, the phase diagrams of TPGS and polyethylene glycol 400 (PEG 400) in the presence of either water or ethanol were constructed. The effect of water and ethanol on the cloud point temperature of TPGS-PEG 400 mixtures was investigated. In general, the cloud point temperature was reduced by the presence of either water or ethanol in the formulation. However, water was more effective in lowering the cloud point temperature than ethanol. Similarly, the phase diagram of TPGS-PEG 1450 was constructed. The cloud point temperature was observed to decrease with increasing TPGS concentration. It was found that TPGS and PEG 1450 could form a single phase when TPGS concentration was above $75 \%$, based on differential scanning calorimetry, and FT-Raman analysis indicated that a vibration at $1330 \mathrm{~cm}^{-1}$ disappeared in the melted single phase. In addition, a systematic melting point depression was observed for the mixtures of TPGS-PEG 1450. In the presence of Ibuprofen, a model compound, the cloud point temperature was also reduced. Finally, the extended Flory-Huggins theory for polymer solution was used to analyze the entropic and enthalpic contributions of water and ethanol to the free energy of mixing. (C) 2011 Wiley-Liss, Inc. and the American Pharmacists Association J Pharm Sci 100:4907-4921, 2011

Keywords: polymers; physical stability; thermal analysis; precipitation; formulation; Raman spectroscopy; semi-solids; surfactants; X-ray; powder diffractometry
\end{abstract}

\section{INTRODUCTION}

The number of drug candidates entering development has significantly increased largely due to the implementation of high throughput screening technology in the pharmaceutical industry. ${ }^{1,2}$ Many candidates have good permeability, but poor water solubility, limiting their bioavailability. They are typically classified as class 2 according to the biopharmaceutical classification system. ${ }^{3}$ To enhance their oral absorption, both solubilized and emulsified liquid formulations have been used to deliver these compounds. ${ }^{4}$ D-alpha-tocopheryl polyethylene glycol succinate (TPGS), polyethylene glycol 400 (PEG 400), and combinations of TPGS with PEG 400 are widely

Correspondence to: Jinjiang Li (Telephone: +732-227-6584; Fax: +732-227-3784; E-mail: jinjiang.li@bms.com)

Journal of Pharmaceutical Sciences, Vol. 100, 4907-4921 (2011) (C) 2011 Wiley-Liss, Inc. and the American Pharmacists Association utilized in preclinical and early phase formulations as well as commercial products for improving the thermodynamic solubility, eliminating the effect of particle size of active pharmaceutical ingredients (API), and maintaining the "crash resistance" of formulations in the gastrointestinal tract, in which a drug molecule is kept in a supersaturation state to enhance the oral absorption of API. ${ }^{5}$ Examples include formulations of docetaxel and paclitaxel, containing TPGS and ethanol, ${ }^{6,7}$ and commercial formulations of Tipranavir and Amprenavir, ${ }^{8,9}$ in which TPGS, PEG 400 , and ethanol are important components. Both Tipranavir and Amprenavir are delivered in softgel capsules, in which formulations are exposed to water during the manufacturing process. Besides their usage in formulations for oral delivery, TPGS, PEG 400, water, and ethanol are also used in formulations delivering drugs transdermally or topically. ${ }^{10}$ In addition, a combination of TPGS with high molecular weight 
PEG such as 1450 is often used to prepare semisolid formulations to deliver drugs in hard gelatin capsules. Furthermore, solid dispersions of API, TPGS, and high molecular weight PEG were prepared for many compounds such as halofantrine. ${ }^{11}$ Therefore, fundamentally, understanding the phase behavior of formulation components such as TPGS, PEG 400, PEG 1450 , ethanol, and water is critical to improve the formulation performance. Even though the phase behavior of systems containing TPGS is not well understood, the phase diagrams of binary systems of PEG/water, PEG/ethanol, and their physical properties, including vapor pressure, heat of mixing, and so on, have been reported..$^{12-14}$ Similarly, many ternary systems consisting of poly(ethylene glycol) were constructed as well. ${ }^{15}$ Theoretically, both Flory-Huggins $(\mathrm{F}-\mathrm{H})$ theory and the extended $\mathrm{F}-\mathrm{H}$ theories with consideration of specific interactions were used to analyze the coexistence of upper critical solution temperature and low critical solution temperature for PEG/ water system. ${ }^{15-17}$

Experimentally, cloud point temperature curves, in which phase separation temperature was plotted against the composition, were often constructed to investigate phase separation phenomena for systems involving polymers. ${ }^{18-20}$ The cloud point curves of the PEG/water system at varying molecular weight distributions were reported by Saraiva et al. ${ }^{21}$ However, a systematic study on the phase behaviors of systems containing TPGS and PEGs in water or ethanol is still missing. In this paper, TPGS, PEG 400, and PEG 1450 were selected as the major formulation components (see Fig. 1 for their chemical structures). Cloud point temperature curves were constructed for TPGS-PEG 400, TPGS-PEG 400/water, TPGS-PEG 400/ethanol, and TPGS-PEG1450 systems because formulations are often exposed to water during manufacturing and ethanol is frequently added in formulations to solubilize the drug. In addition, the composition of the solid phase was studied using X-ray powder diffraction (XRPD), differential scanning calorimetry (DSC), and FT-Raman spectroscopy. To closely simulate a pharmaceutical formulation, a model compound, ibuprofen (see Fig. 1), was selected to be incorporated into all phases, and the impact of the compound on phaseseparation temperature was investigated. Finally, an extended F-H theory, over-simplified for the current systems, but could still serve as a qualitative guidance for excipient selection, was used to analyze the data.

\section{Experimental}

\section{Materials}

Vitamin E TPGS was purchased from Eastman Chemical Company (Kingsport, Tennessee). PEG

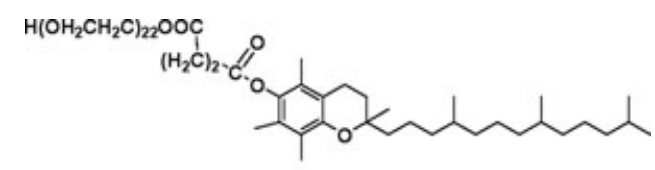

(a)

\section{$\mathrm{OH}\left(\mathrm{CH}_{2} \mathrm{CH}_{2} \mathrm{O}\right) \mathrm{nH}$}

(b)

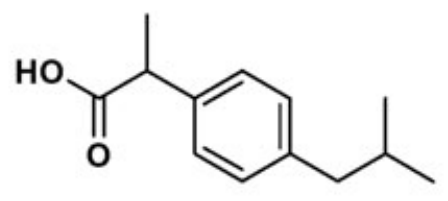

(c)

Figure 1. Chemical structures of (a) TPGS, (b) PEG (PEG $400, n=9$; and PEG 1450, $n=32$ ), and (c) ibuprofen.

400 and PEG 1450 were purchased from the Dow Chemical Company (Midland, Michigan). Water used was obtained using a Milli Q-UV plus water purification system from the Millipore Company (Billerica, Massachusetts). Ethanol (absolute), purchased from Sigma-Aldrich Chemicals, Inc. (Milwaukee, Wisconsin), was used. Ibuprofen, obtained from SigmaAldrich Chemicals, Inc., was used as a model compound.

\section{Experimental}

\section{Construction of Cloud Point Curves}

\section{TPGS-PEG 400/Water/Ethanol}

A Symyx Core Module (Symyx Technologies Inc., Santa Clara, CA) assembly with an automated liquid handling system, fitted with $250-\mathrm{mL}$ positive displacement pipette tips, a 22-gauge solvent delivery piercing needle, an embedded Watlow heating bay (Watlow Process Systems, Wright City, Missouri), and an embedded VP-Scientific tumble stirrer (VPScientific, Inc., San Diego, CA), is used for sample preparation and incubation. Symyx Lab Execution and Analysis software (Symyx Technologies Inc., Santa Clara, CA) was used to control all hardware as well as to design and execute the dispensing of the composition maps of Ibuprofen, PEG 1450, PEG 400, TPGS, water, and ethanol into 1-mL, 96-well plates.

To construct phase diagrams, the following procedures were performed: PEG 400 is liquid at room temperature; however, PEG 1450 and TPGS are solid with melting points of approximately $47^{\circ} \mathrm{C}$ and $36^{\circ} \mathrm{C}$, respectively. Aliquots of PEG 400, PEG 1450, and TPGS were isolated in $20-\mathrm{mL}$ scintillation vials as stocks and each were heated to $43^{\circ} \mathrm{C}-45^{\circ} \mathrm{C}$ or $50^{\circ} \mathrm{C}-55^{\circ} \mathrm{C}$ for 
samples with and without PEG 1450, respectively, to liquefy TPGS and PEG 1450. A nominal density of the two components was determined at the incubation temperature. PEG 400 or molten PEG 1450 and molten TPGS were then transferred volumetrically to 1-mL glass vials in fitted aluminum, 96-well plates to desired proportions. The sources and destinations of this transfer were maintained at $43^{\circ} \mathrm{C}-45^{\circ} \mathrm{C}$ or $50^{\circ} \mathrm{C}-55^{\circ} \mathrm{C}$ by the embedded Watlow heating device. Samples remained at the elevated temperature until the initiation of the study. Samples were tumble stirred during preparation to ensure homogeneity, with paraylene-coated magnetic stir bars and the embedded VP-Scientific tumble stirrer. Stirring was turned off to avoid bubble formation during the incubation process once sample preparation was complete. Sample vials were capped with a polypropylene cap mat that fit snug into each vial. The cap mat was secured by screwing an aluminum retainer plate down onto the mat. Water and ethanol were added to the plates with a piercing needle on the Symyx Core Module, penetrating the "resealable" polypropylene cap. Samples were heated and stirred during this addition to ensure homogeneity. Once whole solvent was delivered to the plate, the cap mat was replaced with a mat that had not been pierced. To observe the cloud point where a phase separation occurs, the temperature was reduced to target an initial sample temperature of $38^{\circ} \mathrm{C}$, and was lowered by $0.5^{\circ} \mathrm{C}$ each time and maintained at each temperature point for $24 \mathrm{~h}$, at which point the phase separation was typically completed. This was verified by monitoring the kinetics of phase separation for $72 \mathrm{~h}$. At each temperature point, the cap mat was removed and samples were assessed visually for any cloudiness. A cloud point was recorded at the first sign of cloudiness. All samples that showed cloudiness were recorded and the actual temperature was measured using a digital thermometer. The blue cap mat and aluminum retainer plate were replaced back to their positions after observation, and the temperature was set to a new set point. The initial experiments were repeated and cloud point temperatures of the samples were observed with $\mathrm{a} \pm 0.25^{\circ} \mathrm{C}$ variability. Visual observation of cloud point was also confirmed using a molecular device spectra spectrometer (Max M12) from Molecular Devices Corporation (Sunnyvale, California).

\section{Mixtures of TPGS-PEG 1450}

To prepare TPGS-PEG 1450 mixtures, the desired amounts of TPGS and PEG 1450 were manually weighed out based on a weight to weight ratio. Then both materials were transferred into a $20-\mathrm{mL}$ scintillation vial followed by heating the vial to melt both TPGS and PEG 1450. This procedure was repeated for all TPGS-PEG $1450(\mathrm{w} / \mathrm{w})$ ratios. All samples were liquefied by heating and were mixed for a few min- utes. Then all vials were placed in an oven for observing the cloud point. The initial temperature was set to $50^{\circ} \mathrm{C}$ and $1{ }^{\circ} \mathrm{C}$ decrements were used to lower the oven temperature, and the observed cloud point temperature had $\mathrm{a} \pm 0.5^{\circ} \mathrm{C}$ variability. Samples were maintained at each temperature for $24 \mathrm{~h}$.

\section{Mixtures of TPGS-PEG 400 or PEG 1450-Ibuprofen}

Ibuprofen samples were prepared using the procedure described previously. Ibuprofen was dissolved in PEG and PEG-TPGS stock samples prior to sample dispensing. Target concentrations were achieved through a combination of stock ibuprofen solutions and neat solvents based on a nominal density.

\section{X-Ray Powder Diffraction}

All XRPD patterns were obtained at room temperature using a Philips X'pert 3050 X-ray diffractometer (Philips, Almelo, The Netherlands) at $40 \mathrm{~mA}$ and $45 \mathrm{kV}$ with $\mathrm{Cu} \mathrm{K} \alpha$ radiation. A flat plate sample holder was used for all samples. All scans were performed within $2 \theta$ angle range of $2^{\circ}-32^{\circ}$, with a step size of $0.03^{\circ}(2 \theta)$ using a scanning rate of one step per second. To ensure no sample orientation effect, all samples were rotated during measurement.

\section{Differential Scanning Calorimetry}

A TA Q1000 DSC (TA Instruments, New Castle, Delaware) was used to analyze the binary mixtures of TPGS and PEG 1450 . Approximately $5-10 \mathrm{mg}$ of each mixture of TPGS to PEG 1450 was first weighed out and then transferred into an aluminum DSC pan followed by sealing the pan. A pin hole was made in each DSC pan with a needle to allow release of potential volatiles. This procedure was repeated for all TPGS-PEG 1450 mixtures. Then all DSC pans were placed in the DSC carousel followed by initiation of the run. The melted mixtures of TPGS-PEG 1450 samples were prepared by heating physical mixtures to a liquid state followed by cooling. Crystallization of the TPGS-PEG 1450 mixture was monitored by heating the mixture to the liquid state in a DSC pan followed by slow cooling. A scan range of $-20^{\circ} \mathrm{C}$ to $100^{\circ} \mathrm{C}$ was used, and a scanning rate of $1^{\circ} \mathrm{C} / \mathrm{min}$ was employed for all samples.

\section{FT-Raman Measurement}

A PhAT Raman (sn) system equipped with a near infrared laser with a typical power output of $100 \mathrm{~mW}$ (purchased from Kaiser Optical Systems, Inc.; Ann arbor, Michigan) was used to record all FT-Raman spectra at $785 \mathrm{~nm}$ laser excitation. The PhAT probe used was a noncontact Raman probe with $6-\mathrm{mm}$ spot size and 250-mm focal length. Backscattering was at $180^{\circ}$ and Stokes scattering was reported. The sample exposure time varied from 5 to $20 \mathrm{~s}$ depending on the sample, which resulted in a scan number variation of 
1-4. Spectra obtained ranged from 0 to $1900 \mathrm{~cm}^{-1}$ and the resolution was $0.3 \mathrm{~cm}^{-1}$.

\section{RESULTS}

The phase behavior of combinations of common excipients, TPGS-PEG 400, TPGS-PEG 400-water, TPGS-PEG 400-ethanol, and TPGS-PEG 1450, which are typically used to deliver poorly watersoluble compounds, has been investigated in this paper. The results are reported in the following sections. Because cloud point temperature is influenced by the purity of polymers and their molecular weight distribution, and such parameters may vary from supplier to supplier, it is important to note that the cloud point values shown in this article are specific to the manufacturers of the materials used in this study.

\section{Mixtures of TPGS-PEG 400}

In Figure 2, the cloud point temperature or phase separation temperature $\left(T_{\mathrm{c}}\right)$, which is the upper critical solution temperature at which any decrease of temperature will cause phase separation, is plotted as a function of TPGS concentration (w/w \%) in the TPGS-PEG 400 binary mixtures. As indicated in Figure 2, TPGS and PEG 400 formed a single liquid phase above Tc. The TPGS and PEG 400 system separated into two phases, liquid and solid, when the temperature was lowered to below $T_{\mathrm{c}}$, which is likely due to the phase separation of PEG 400 and TPGS followed by crystallization of TPGS. In general, as seen from Figure 2, the cloud point temperature increases with TPGS concentration or $T_{\mathrm{c}}$ decreases with PEG 400 concentration, which is probably due to the fact that TPGS has a higher melting point than PEG 400. As for the phase composition at a temperature $(T)$ less than $T_{\mathrm{c}}$, it consists of solid TPGS and liquid PEG 400 as indicated below. Figure 3 shows the XRPD patterns of a TPGS-PEG 400 mixture (50:50) at $T<T_{\text {c }}$ as well as TPGS alone. As shown in Figure 3, the XRPD pattern of TPGS-PEG 400 mixture at $T<T_{\mathrm{c}}$

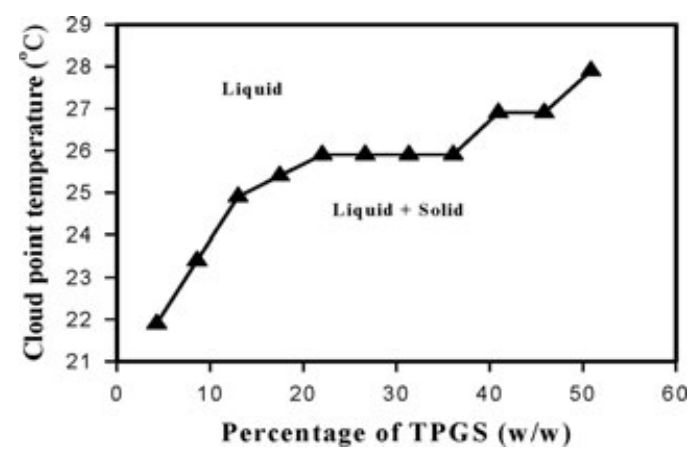

Figure 2. Phase diagram of TPGS-PEG 400 mixtures: top is the liquid phase and bottom is a mixture of solid and liquid $(\mathrm{w} / \mathrm{w})$. matches exactly that of TPGS alone, indicating that majority of the crystalline phase in the TPGS-PEG 400 mixture $\left(T<T_{\mathrm{c}}\right)$ is TPGS given that PEG 400 is liquid at room temperature, and PEG 400 has a freezing point of $4-8^{\circ} \mathrm{C}$. However, the phase behavior of TPGS-PEG 400 changed significantly when water was added to the system. Figure 4 shows the phase diagram of TPGS-PEG 400-water with water concentrations varying from $0 \%$ to $20 \%$. As shown in Figure 4, the cloud point temperature of TPGS-PEG 400 consistently decreased with increasing water concentration. At $5 \%$ water $(\mathrm{w} / \mathrm{w})$ concentration, $T_{\mathrm{c}}$ was slightly reduced at a TPGS concentration less than $35 \%$, and it remained the same as that without water when the TPGS concentration was increased to greater than $35 \%$. At a water concentration of $10 \%, T_{\mathrm{c}}$ was further reduced, where it first plateau with TPGS concentrations up to $35 \%$, followed by an increase as the concentration of TPGS increased. This suggests that there is a strong interaction between water and PEG 400/TPGS in the TPGS concentration range of $0 \%-35 \%$. Beyond $35 \%, T_{\mathrm{c}}$ is mainly affected by TPGS because TPGS is in excess. When water concentration was further increased to $15 \%, T_{\mathrm{c}}$ was reduced to about $18^{\circ} \mathrm{C}$ and it remained unchanged over the concentration range of TPGS studied, suggesting that there are enough water molecules to interact with both TPGS and PEG 400 so that both PEG 400-water and TPGS-water interactions become dominant. As indicated in Figure 4, at a $20 \%$ water concentration, $T_{\mathrm{c}}$ of TPGS-PEG 400 was reduced to about $15^{\circ} \mathrm{C}$, and gel formation was observed at a TPGS concentration greater than $35 \%$, an indication of even stronger PEG 400-water/TPGS-water interactions. In addition, at this concentration of water, TPGS or PEG 400 may form other phase structures, which are beyond the detection method discussed in this paper.

Similarly, the effect of ethanol on the phase behavior of TPGS-PEG 400 is shown in Figure 5. In Figure 5, $T_{\mathrm{c}}$ of TPGS-PEG 400-ethanol is plotted as a function of TPGS concentration for TPGS-PEG 400-ethanol mixtures with ethanol concentrations varying from $0 \%$ to $25 \%$. Similar to the mixtures of TPGS-PEG 400-water, $T_{\mathrm{c}}$ decreased with an increasing concentration of ethanol, but the magnitude of the reduction of $T_{\mathrm{c}}$ is much smaller. In other words, compared with water, ethanol had less impact on the phase behavior of TPGS-PEG 400 in terms of reducing $T_{\mathrm{c}}$. In addition, $T_{\mathrm{c}}$ almost always increased with increasing TPGS concentration for all mixtures in the ethanol concentration range of $0 \%-25 \%$. It is also noted that for TPGS-PEG 400-ethanol mixtures with $20 \%$ and $25 \%$ ethanol, $T_{\mathrm{c}}$ overlapped almost throughout the entire TPGS concentration range. Furthermore, no formation of gel was observed for the mixtures of TPGS-PEG 400-ethanol. 


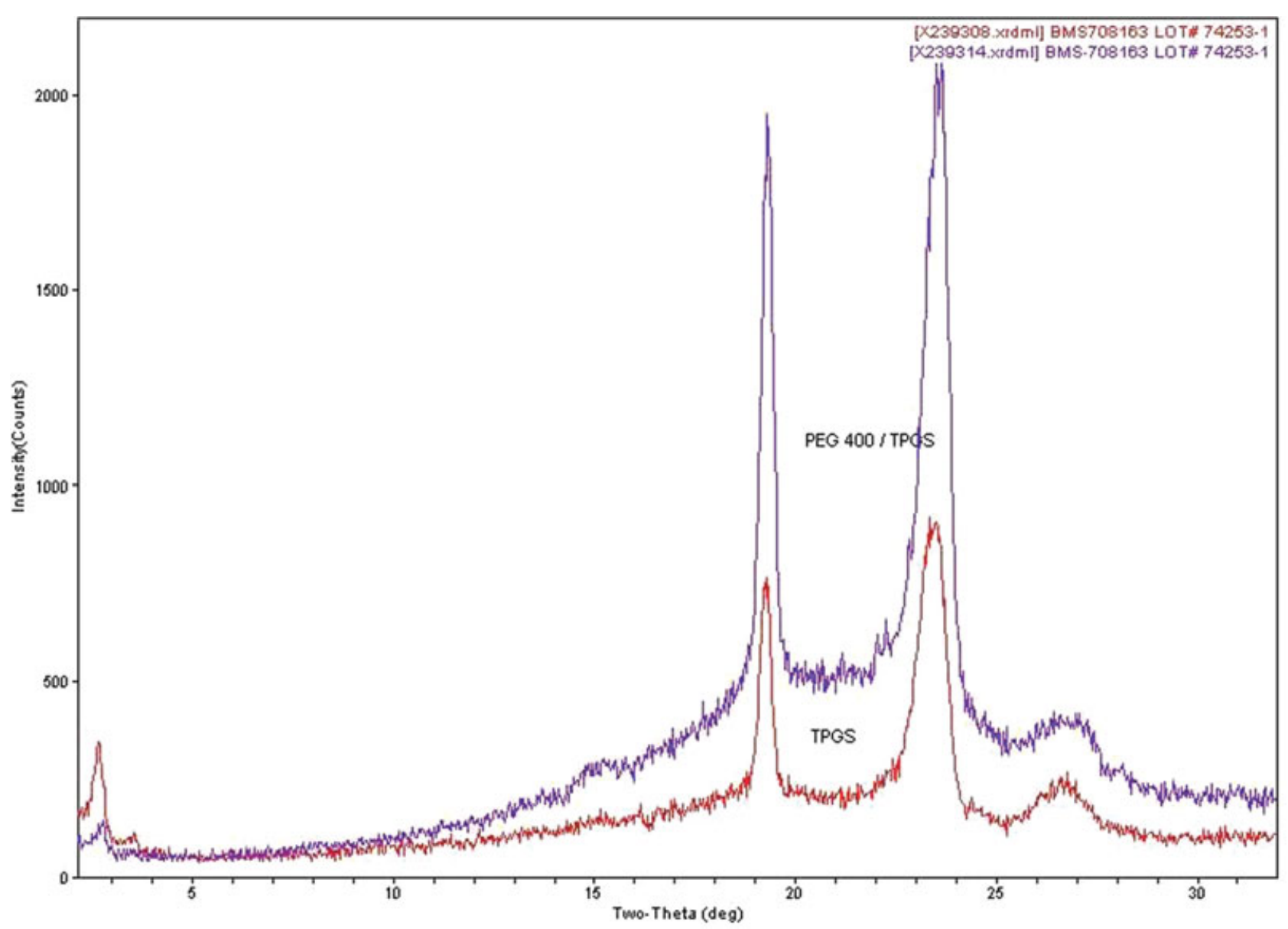

Figure 3. XRPD patterns of TPGS-PEG 400 mixtures phase at room temperature: (bottom) TPGS and (top) mixture of TPGS-PEG 400 (50:50, w/w).

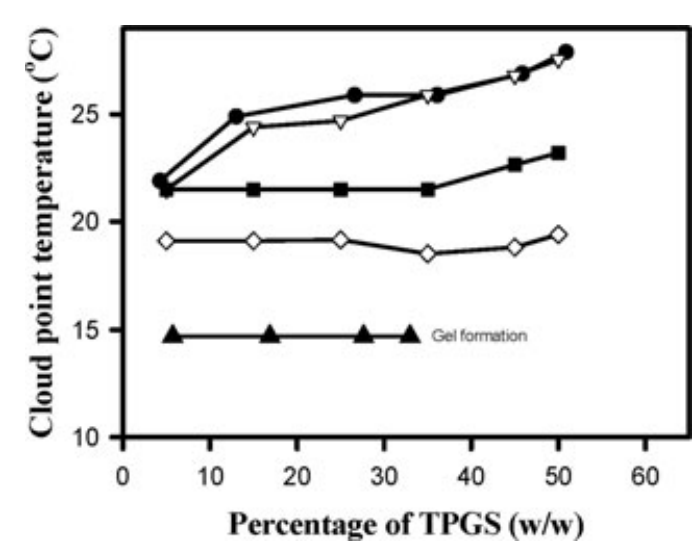

Figure 4. Phase diagram of TPGS-PEG 400-water mixtures: $(\bullet) 0 \%$ water $(\mathrm{w} / \mathrm{w}),(\nabla) 5 \%$ water $(\mathrm{w} / \mathrm{w}),(\boldsymbol{\square}) 10 \%$ water $(\mathrm{w} / \mathrm{w}),(\diamond) 15 \%$ water $(\mathrm{w} / \mathrm{w})$, and $(\boldsymbol{\Delta}) 20 \%$ water $(\mathrm{w} / \mathrm{w})$.

\section{Mixtures of TPGS-PEG 1450}

In Figure 6, $T_{\mathrm{c}}$ of TPGS-PEG 1450 mixtures is plotted as a function of TPGS concentration. As shown in Figure $6, T_{\mathrm{c}}$ was observed to remain almost constant and then decreased with increasing TPGS concentration at a TPGS concentration greater than $65 \%$. This is

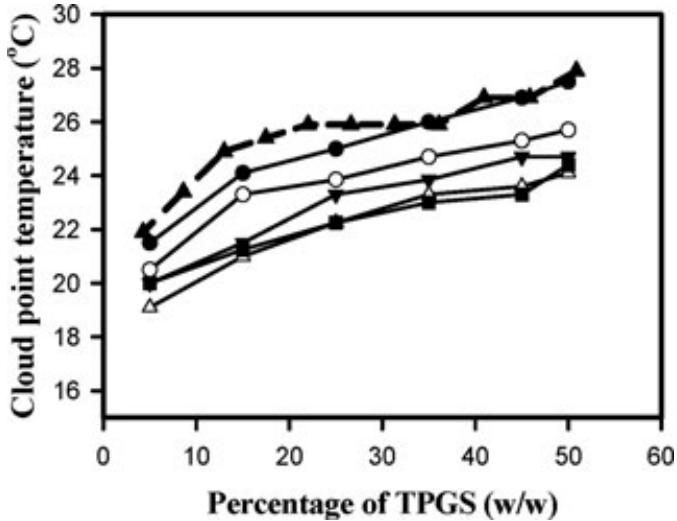

Figure 5. Phase diagram of TPGS-PEG 400-ethanol

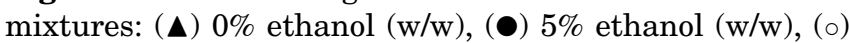
$10 \%$ ethanol $(\mathrm{w} / \mathrm{w}),(\triangleleft) 15 \%$ ethanol $(\mathrm{w} / \mathrm{w}),(\triangle) 20 \%$ ethanol (w/w), and (ם) $25 \%$ ethanol (w/w).

because TPGS has a lower melting point $\left(37^{\circ} \mathrm{C}-40^{\circ} \mathrm{C}\right)$ than PEG $1450\left(44^{\circ} \mathrm{C}-48^{\circ} \mathrm{C}\right)$. TPGS and PEG 1450 formed a single liquid phase at $T>T_{\mathrm{c}}$ and they formed solid phases at $T<T_{\text {c }}$. However, it was difficult to identify the solid phase composition using XRPD 


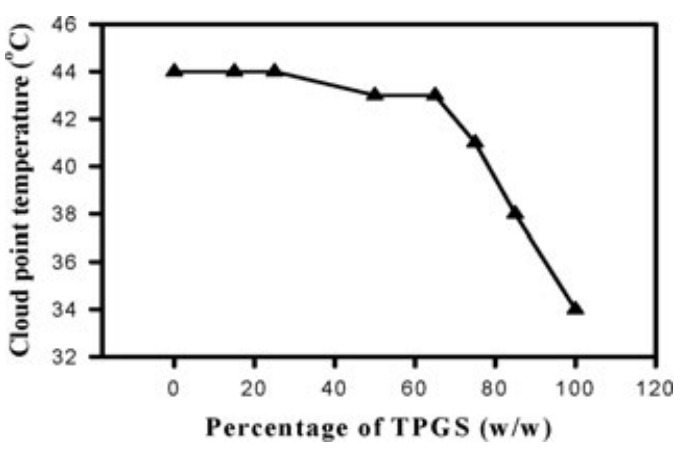

Figure 6. Phase diagram of TPGS-PEG 1450 (w/w).

because TPGS and PEG 1450 have similar XRPD patterns (see Fig. 7). Figure 7 shows the XRPD patterns of the TPGS-PEG 1450 mixture (melted) with $75 \%(\mathrm{w} / \mathrm{w})$ TPGS, the corresponding physical mixture of TPGS-PEG 1450, TPGS alone, PEG 1450 alone, and a silica reference. The XRPD pattern of melted TPGS-PEG 1450 mixture matched that of the physical mixture as well as that of TPGS alone and PEG 1450 alone due to the structural similarity between TPGS and PEG 1450 (see Fig. 1). On the contrary, the melted mixtures of TPGS with PEG 1450 behaved thermally different from the physical mixture of TPGS and PEG 1450, as indicated by DSC (see Figs. 8, 9, and 10). Figure 8 shows the DSC thermograms of the physical mixture of TPGS-PEG 1450 (25:75, w/w), TPGS, and PEG 1450. As indicated in Figure 8, the physical mixture of TPGS with PEG 1450 exhibited two melting endotherms corresponding to the melting endotherms of the individual components. Figure 9 shows the melting behavior of the mixtures of TPGS-PEG 1450 with TPGS concentrations varying from $10 \%$ to $90 \%$ (w/w), which were prepared by heating the two components to liquid state followed by cooling. As shown in Figure 9, the endotherms of TPGS and PEG 1450 completely merged into one at a TPGS concentration of $75 \%(\mathrm{w} / \mathrm{w})$, a possible indication of the formation of a single phase. Similarly, as seen in Figure 10, the crystallization behavior of TPGS-PEG 1450 mixtures was monitored by DSC, in which the crystallization temperature was found to decrease with increasing TPGS concentration. To further explore the formation of a single phase between PEG 1450 and TPGS, FT-Raman spectra were acquired (see Fig. 11). In Figure 11, the Raman

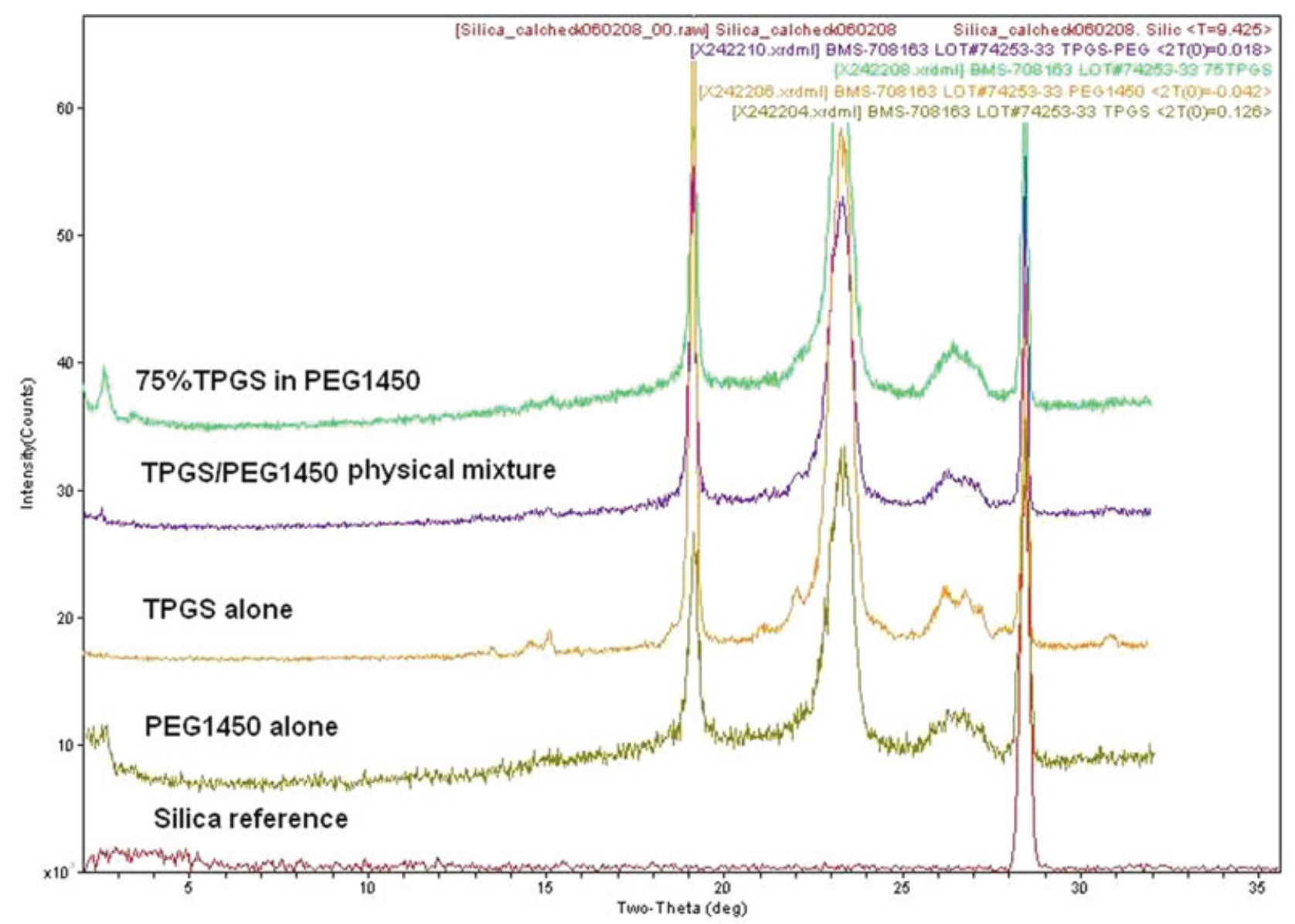

Figure 7. XRPD patterns of silica reference, PEG 1450, TPGS, physical mixture of TPGS-PEG 1450 (75:25, w/w), and melted mixture of TPGS-PEG 1450 (75:25, w/w) (from bottom to top). 


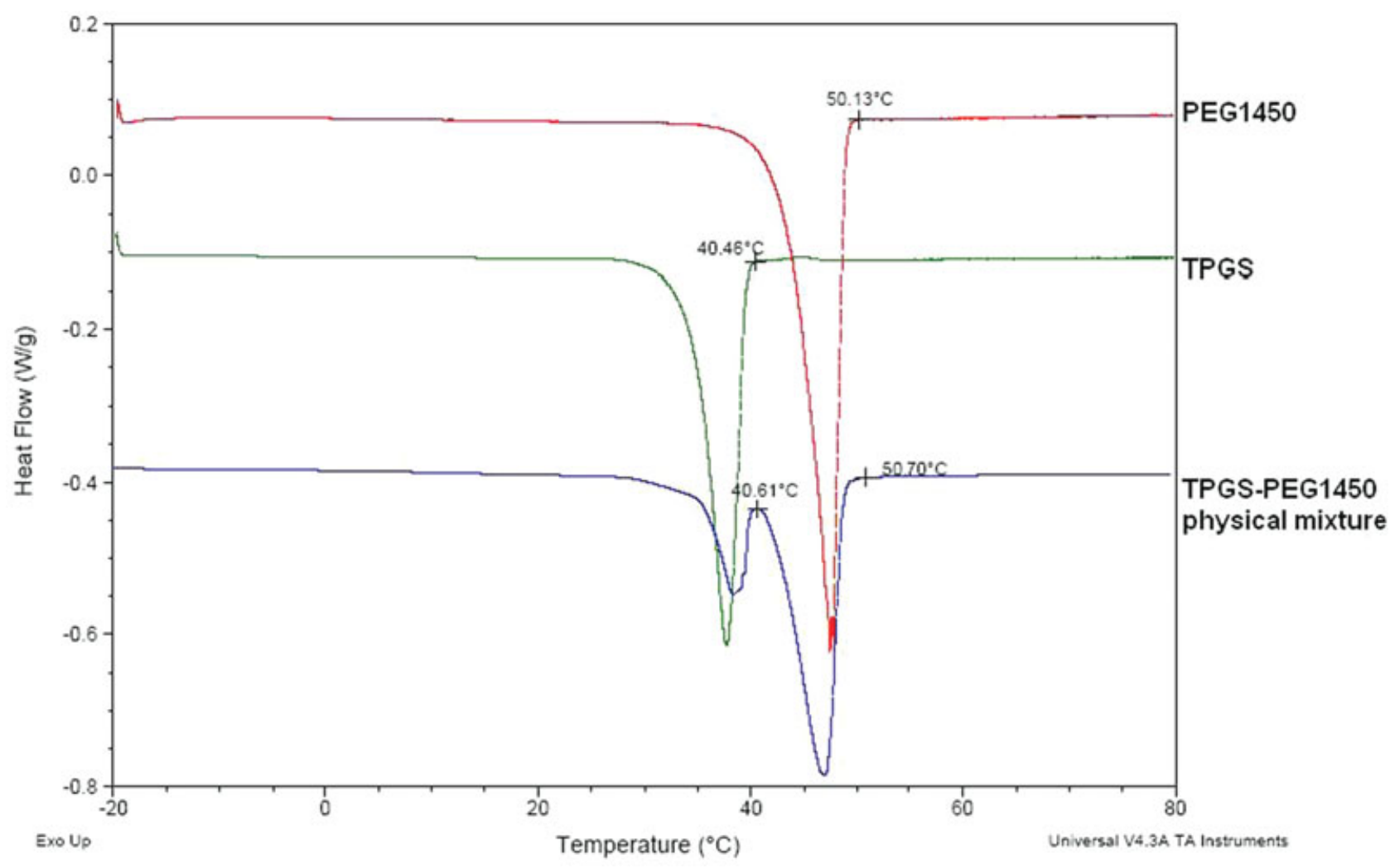

Figure 8. DSC thermograms of TPGS-PEG 1450 physical mixture (50:50, w/w), TPGS, and PEG 1450 (from bottom to top).

spectra of PEG 1450, the physical mixture of TPGS and PEG 1450, TPGS, and the melted phase of TPGS and PEG 1450 are shown. Raman spectra for all samples appeared very similar except for TPGS alone. The physical mixture of TPGS and PEG 1450 has a vibration at $1330 \mathrm{~cm}^{-1}$, which disappeared from the melted phase of TPGS and PEG 1450 (75:25, w/w). The observed vibrations can be classified into two groups based on their vibration modes: $\mathrm{CH}_{2}$ scissor and $\mathrm{CH}_{2}$ wag. ${ }^{22-24}$ Vibrations around 1486, 1480, 1447, and $1397 \mathrm{~cm}^{-1}$ belong to $\mathrm{CH}_{2}$ scissor and the vibrations around $1364 \mathrm{~cm}^{-1}$ is due to $\mathrm{CH}_{2}$ wag. ${ }^{23}$ Both PEG 1450 and TPGS showed these vibrations because part of TPGS is PEG 1000, which has the same repeating unit as PEG 1450. However, the vibration around $1330 \mathrm{~cm}^{-1}$ was only observed for TPGS and the physical mixture of TPGS and PEG 1450, which is probably due to a - $\mathrm{CH}$ or ring vibration of the Vitamin $\mathrm{E}$ portion of TPGS. ${ }^{22-24}$ This vibration might be associated with the crystalline structure of TPGS. As seen from Figure 11, the peak around $1330 \mathrm{~cm}^{-1}$ disappeared for the melted phase of TPGS and PEG 1450.

\section{Mixtures of TPGS-PEG 400/1450-Ibuprofen}

In Figures 12 and 13, the phase diagrams for TPGS-PEG 400-ibuprofen and TPGS-PEG 1450-ibuprofen mixtures are shown. As indicated in Figures 12 and 13, $T_{\mathrm{c}}$ was significantly reduced for both TPGS-PEG 400 and TPGS-PEG $1450 \mathrm{mix}-$ tures in the presence of ibuprofen, in which $T_{\mathrm{c}}$ consistently decreased with increasing concentrations of ibuprofen, an indication of a strong interaction between ibuprofen and other components. As shown in Figure 12, $T_{\mathrm{c}}$ increased with increasing TPGS concentration for all mixtures except for the mixture with $25 \%$ ibuprofen. At 25\% (w/w) ibuprofen, $T_{\mathrm{c}}$ remained constant for TPGS-PEG 400-ibuprofen mixtures until the TPGS concentration reached above $30 \%$ (w/w). For the TPGS-PEG 1450-ibuprofen mixtures it was noticed that there was a slight decrease in $T_{\mathrm{c}}$ with TPGS concentration for all ibuprofen concentrations (Fig. 13). This was expected because the melting temperature of TPGS is lower than that of PEG 1450 .

\section{DISCUSSION}

Chemically, PEG 400 and PEG 1450 have the same repeating unit, $-\mathrm{OCH}_{2}$, except that $\mathrm{PEG} 1450$ is a larger molecule (see Fig. 1). TPGS is a succinated conjugate of PEG 1000 with Vitamin E. Its structure is shown in Figure 1. These materials have properties between small molecules and polymers because their molecular weight is higher than that of a typical small molecule and lower than that of a typical 


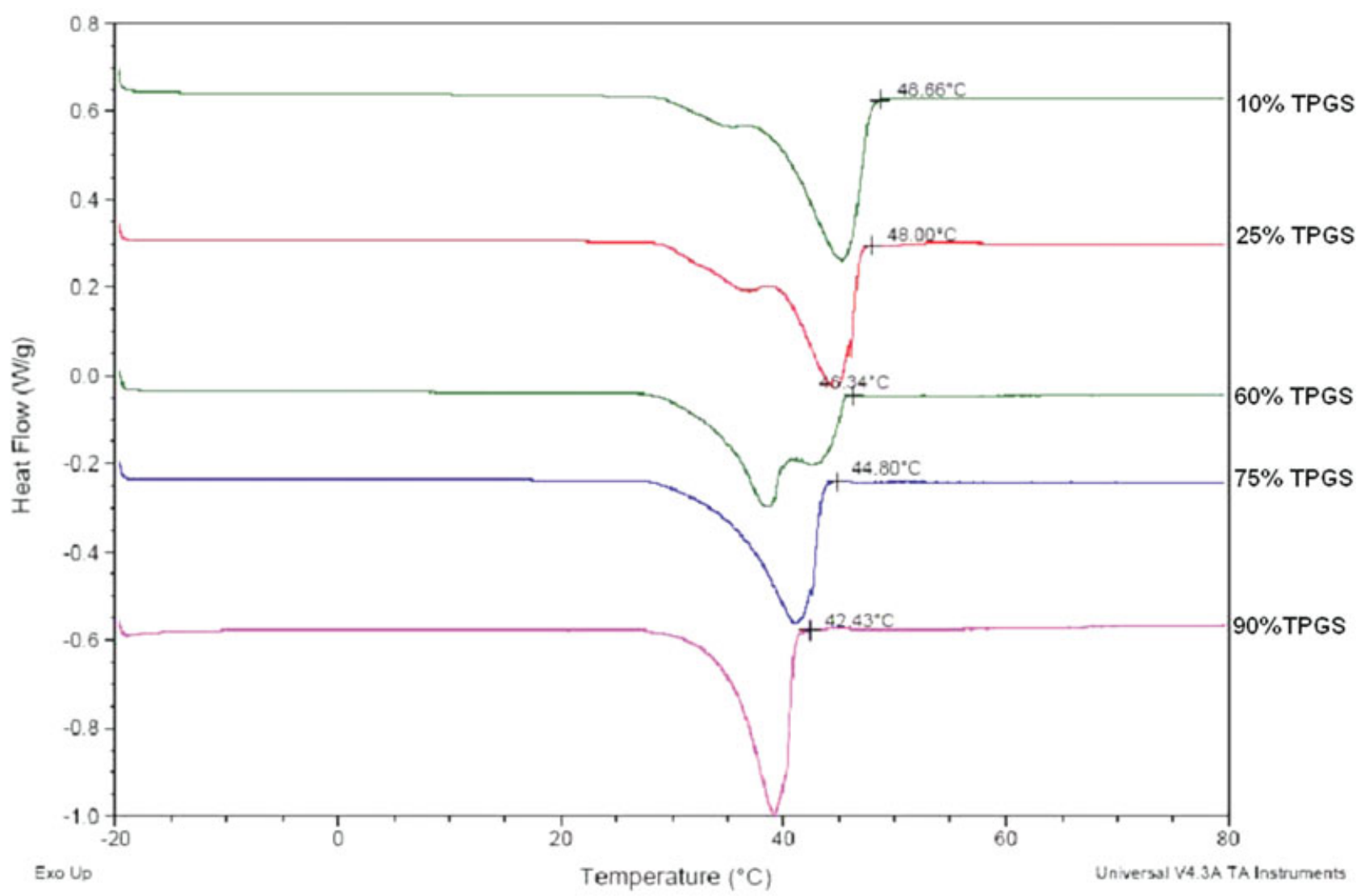

Figure 9. DSC melting thermograms of melted TPGS-PEG 1450 mixtures: (from bottom to top) $90 \%$ TPGS (w/w), 75\% TPGS (w/w), 60\% TPGS (w/w), 25\% TPGS (w/w), and 10\% TPGS $(\mathrm{w} / \mathrm{w})$.

macromolecule even though TPGS is surface active. In this paper, the F-H theory, which takes the connectivity of monomers into consideration, was used to understand the phase behavior of these systems, although for practical systems described in this paper, this theory is oversimplified. ${ }^{25}$ In particular, interpretation of $\mathrm{F}-\mathrm{H}$ interaction parameter $(\chi)$ is becoming more difficult for systems with specific interactions. ${ }^{26}$ The first version of the $\mathrm{F}-\mathrm{H}$ theory (zero approximation) considered only endothermic mixing, which is true for systems involving only dispersion forces, and $\chi \geq 0$, meaning that the entropy is the driving force for mixing. ${ }^{27}$ In practice, $\chi$ is semiempirical, which also consists of a nonzero noncombinatorial entropic contribution $\left(\chi=\chi_{\mathrm{H}}+\chi_{\mathrm{S}}\right)$. In general, $\chi$ for a practical system depends on many factors, including temperature, polymer concentration, the molecular weight distribution of polymers, and so on. ${ }^{28}$ Practically, $\chi$ is often treated as a phenomenological parameter, which is often obtained by constructing cloud point curves. ${ }^{29}$ Furthermore, for systems with known interactions such as hydrogen bonding, a free energy term accounting for this specific interaction was introduced into the $\mathrm{F}-\mathrm{H}$ theory. ${ }^{30,31} \mathrm{In}$ this paper, $\mathrm{PEG}$
400, TPGS, and water/or ethanol were chosen for their practical utilities in pharmaceutical formulations. Because PEG 400, water, and ethanol are either small molecules or oligomers, and the contribution of the entropy of mixing to the free energy is significant, the $\mathrm{F}-\mathrm{H}$ theory has been chosen to evaluate this contribution. As known from the literature, mixtures of PEG 400/water or PEG 400/ethanol involve formation of hydrogen bonding ${ }^{32}$ and the original $\mathrm{F}-\mathrm{H}$ theory is not adequate to account for it because it was developed for systems with nonpolar interactions. ${ }^{33}$ An extended $\mathrm{F}-\mathrm{H}$ theory with additional free energy terms accounting for hydrogen bonding will be used in this paper. To simplify the treatment, this paper will stick to the interaction of only two molecular terms and ignore the higher interaction terms. ${ }^{34}$ Similar to the approach taken by Tompa, ${ }^{35}$ PEG 400, TGPS, and water system or PEG 400, TPGS, and ethanol system will be considered as two polymer/oligomer and one solvent system (solvent as component 1 ) with $\chi_{12}=$ $\chi_{13}$. In the following section, the $\mathrm{F}-\mathrm{H}$ theory of mixing two polymers or two polymers with one solvent will be used to analyze the phase equilibria reported in this paper. 


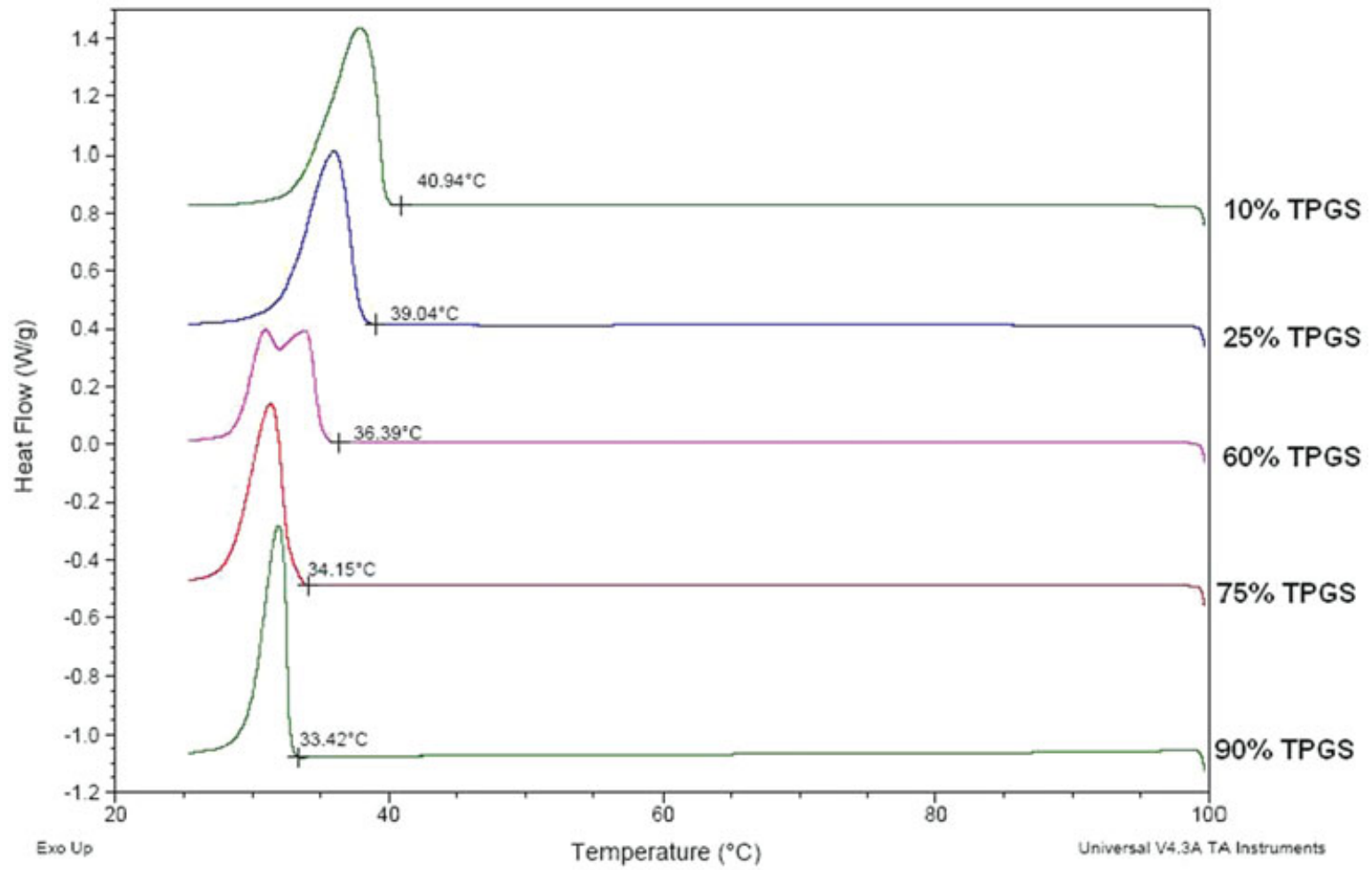

Figure 10. DSC thermograms of crystallization of TPGS-PEG 1450 mixtures (from bottom to top): $90 \%$ TPGS (w/w), 75\% TPGS (w/w), 60\% TPGS (w/w), 25\% TPGS (w/w), and 10\% TPGS $(\mathrm{w} / \mathrm{w})$.

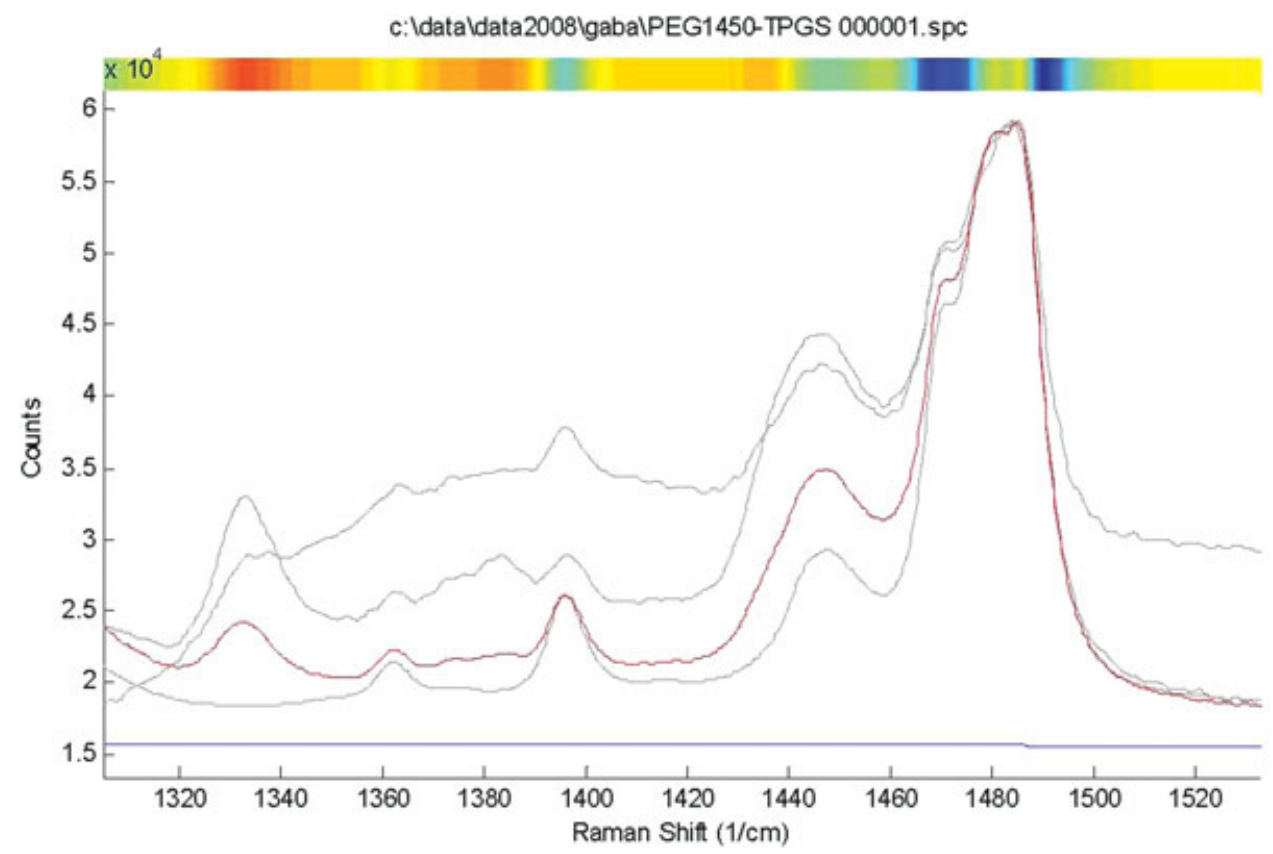

Figure 11. FT-Raman spectra of PEG 1450, physical mixture of TPGS-PEG 1450, TPGS alone, and solid phase from the melted mixture of TPGS-PEG 1450 (75:25, w/w) (from bottom to top). 


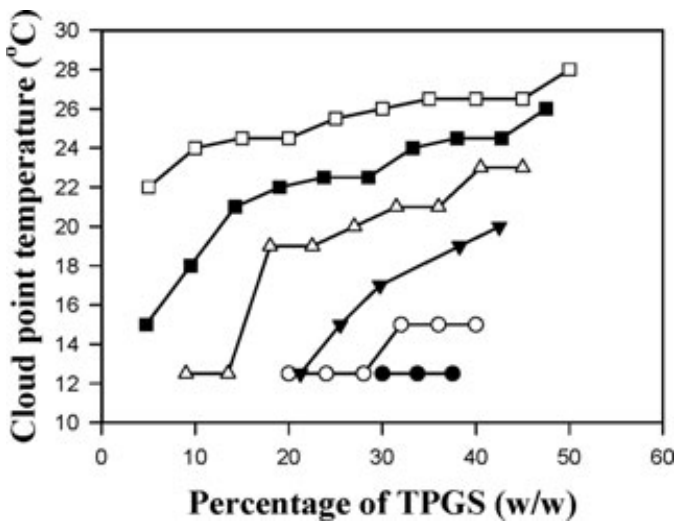

Figure 12. Phase diagrams of TPGS-PEG 400-ibuprofen: ( $\square$ ) $0 \%$ ibuprofen, (ם) $5 \%$ ibuprofen (w/w), $(\triangle) 10 \%$

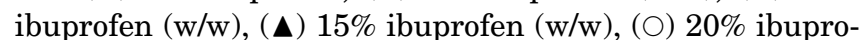
fen (w/w), and (๑) $25 \%$ ibuprofen (w/w).

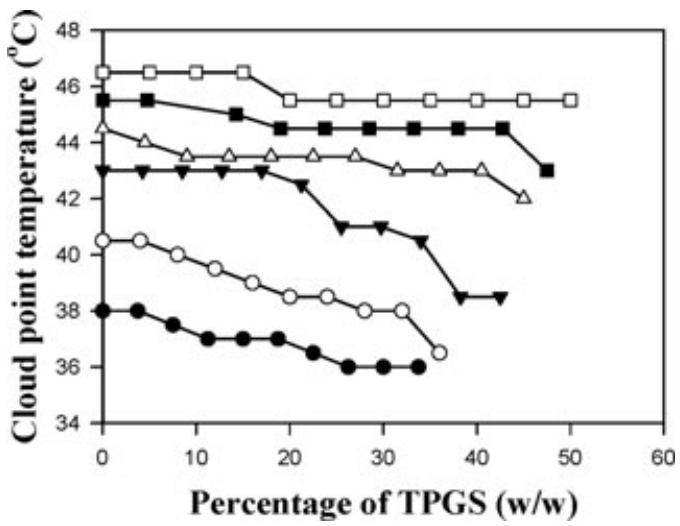

Figure 13. Phase diagram of TPGS-PEG 1450-ibuprofen mixtures: ( $\square$ ) $0 \%$ ibuprofen (w/w), (口) $5 \%$ ibuprofen (w/w),

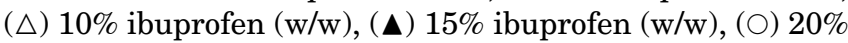
ibuprofen (w/w), and (•) $25 \%$ ibuprofen (w/w).

\section{Theoretical Background}

The original $\mathrm{F}-\mathrm{H}$ free energy of mixing is made of two parts: the entropy of mixing and the enthalpy of mixing. In general, for polymer-polymer mixing or polymer-solvent mixing, the free energy of mixing per unit volume is expressed as below:For binary systems,

$$
\Delta G_{\mathrm{V}}=\frac{R T}{V_{0}}\left[\frac{\phi_{1} \ln \phi_{1}}{n_{1}}+\frac{\phi_{2} \ln \phi_{2}}{n_{2}}+\phi_{1} \phi_{2} \chi\right]
$$

where $V_{0}, \phi_{1}, \phi_{2}, \chi, n_{1}, n_{2}, R$, and $T$ are volume, volume fractions of component 1 and 2 , the $\mathrm{F}-\mathrm{H}$ interaction parameter, the degree of polymerization of components 1 and 2, the gas constant, and the temperature, respectively. For a system with hydrogen bonding interactions, $\Delta G_{\mathrm{H}}$ is added to Equation 1, and Eq.1 can be written as

$$
\begin{aligned}
\Delta G_{\mathrm{V}}= & \frac{R T}{V_{0}}\left[\frac{\phi_{1} \ln \phi_{1}}{n_{1}}+\frac{\phi_{2} \ln \phi_{2}}{n_{2}}+\phi_{1} \phi_{2} \chi\right] \\
& +\Delta G_{\mathrm{H}}
\end{aligned}
$$

Similarly, for a ternary system, the original $\mathrm{F}-\mathrm{H}$ theory is written as

$$
\begin{aligned}
\Delta G_{\mathrm{V}}= & \frac{R T}{V_{0}}\left[\frac{\phi_{1} \ln \phi_{1}}{n_{1}}+\frac{\phi_{2} \ln \phi_{2}}{n_{2}}+\frac{\phi_{3} \ln \phi_{3}}{n_{3}}\right. \\
& \left.+\phi_{1} \phi_{2} \chi_{12}+\phi_{2} \phi_{3} \chi_{23}+\phi_{1} \phi_{3} \chi_{13}\right]
\end{aligned}
$$

where $V_{0}, \phi_{1}, \phi_{2}, \phi_{3}, \chi_{12}, \chi_{23}, \chi_{13}, n_{1}, n_{2}, n_{3}, R$, and $T$ are the volume, volume fractions of components 1,2 , and 3 , the $\mathrm{F}-\mathrm{H}$ interaction parameters of components 1 and 2,2 and 3 , and 1 and 3 , the degree of polymerization of components 1,2 , and 3 , the gas constant, and the temperature, respectively. For a ternary system, three free energy change terms resulting from hydrogen bonding interactions can be added to Equation 3, and Eq. 3 is therefore written as

$$
\begin{aligned}
\Delta G_{\mathrm{V}}= & \frac{R T}{V_{0}}\left[\frac{\phi_{1} \ln \phi_{1}}{n_{1}}+\frac{\phi_{2} \ln \phi_{2}}{n_{2}}+\frac{\phi_{3} \ln \phi_{3}}{n_{3}}\right. \\
& \left.+\phi_{1} \phi_{2} \chi_{12}+\phi_{2} \phi_{3} \chi_{23}+\phi_{1} \phi_{3} \chi_{13}\right] \\
& +\Delta G_{\mathrm{H} 12}+\Delta G_{\mathrm{H} 13}+\Delta G_{\mathrm{H} 23}
\end{aligned}
$$

On the basis of phase stability conditions, both the second and the third derivatives of the free energy of mixing with respect to composition are equal to zero at a phase separation point. However, for both binary and ternary systems, the mathematical derivation could be very lengthy and therefore it is omitted here. In the following discussion, the experimental results will be interpreted qualitatively based on the extended $\mathrm{F}-\mathrm{H}$ theory of mixing. In addition, volume fraction is used in the $\mathrm{F}-\mathrm{H}$ theory instead of the weight fraction, but the conclusion should be still valid given that the density of these materials is mostly around $1 \mathrm{~g} / \mathrm{mL}$.

\section{TPGS-PEG 400 System}

As seen in Figure 2, TPGS and PEG 400 were miscible above the cloud point temperature (above the crystallization temperature of TPGS). $T_{\mathrm{c}}$ increased with TPGS concentration, indicating that there might be some interaction between TPGS and PEG 400. However, based on literature data, it is expected that the nonpolar interactions between PEG 400 and TPGS were very weak and $\chi$ can be treated as zero. ${ }^{36,37}$ Based on Eq. 2, the free energy of mixing for PEG 400 and TPGS is made of entropy, enthalpy (nonpolar interaction), and hydrogen bonding interaction. Given that PEG 400 and PEG 1000 (PEG portion of TPGS) 
Table 1. The Calculated Combinatorial Entropy (in Terms of $R T / V_{0}$ ) of PEG 400-TPGS Binary System

\begin{tabular}{lcc}
\hline $\begin{array}{l}\text { Percentage of } \\
\text { PEG } 400\end{array}$ & $\begin{array}{c}\text { Percentage } \\
\text { of TPGS }\end{array}$ & $\begin{array}{c}\text { Calculated Entropy } \\
\left(R T / V_{0}\right)\left(\mathrm{J} / \mathrm{cm}^{3}\right)^{a}\end{array}$ \\
\hline 95 & 5 & -0.0126 \\
90 & 10 & -0.0219 \\
85 & 15 & -0.0296 \\
80 & 20 & -0.0363 \\
75 & 25 & -0.0420 \\
70 & 30 & -0.0469 \\
65 & 35 & -0.0510 \\
60 & 40 & -0.0542 \\
55 & 45 & -0.0567 \\
50 & 50 & -0.0584 \\
45 & 55 & -0.0592 \\
\hline
\end{tabular}

${ }^{a}\left(R T / V_{0}\right)$ is $68 \mathrm{~J} / \mathrm{cm}^{3}$ assuming at $298 \mathrm{~K}$ if a density value of $1.2 \mathrm{~g} / \mathrm{cm}^{3}$ is used for PEG 400 .

have a degree of polymerization of about 8 and 23 with negligible nonpolar interactions, Eq. 2 can be rewritten as

$$
\Delta G_{\mathrm{V}}=\frac{R T}{V_{0}}\left[\frac{\phi_{1} \ln \phi_{1}}{8}+\frac{\phi_{2} \ln \phi_{2}}{23}\right]+\Delta G_{\mathrm{H}}
$$

In Table 1, the calculated entropy values based on Eq. 5 are listed. As seen in Table 1, the change of entropy $\left(\frac{\phi_{1} \ln \phi_{1}}{8}+\frac{\phi_{2} \ln \phi_{2}}{23}\right)\left(\frac{R T}{V_{0}}\right)$ is very small as the concentration of TPGS is varied from $5 \%$ to $50 \%$ (for instance, assuming temperature is $298 \mathrm{~K}$, the change is only about $3 \mathrm{~J} / \mathrm{cm}^{3}$ ). Because $T_{\mathrm{c}}$ is affected by the composition (see Fig. 2) and the entropy of mixing (a combinatorial term) of the system stays about the same in the concentration range studied, it suggests that there might be hydrogen bonding interaction (the interaction energy of the weakest hydrogen bonding is around $0.5 \mathrm{kcal} / \mathrm{mol}$ ) between TPGS and PEG 400, which affects $T_{\text {c. }}$. For the ternary system with water or ethanol, Eq. 2 can be rewritten as

$$
\begin{aligned}
\Delta G_{\mathrm{V}}=\frac{R T}{V_{0}} & {\left[\frac{\phi_{1} \ln \phi_{1}}{1}+\frac{\phi_{2} \ln \phi_{2}}{8}+\frac{\phi_{3} \ln \phi_{3}}{23}\right.} \\
& \left.+\phi_{1} \phi_{2} \chi_{12}+\phi_{2} \phi_{3} \chi_{23}+\phi_{1} \phi_{3} \chi_{13}\right]+\Delta G_{\mathrm{H} 12} \\
& +\Delta G_{\mathrm{H} 13}+\Delta G_{\mathrm{H} 23}
\end{aligned}
$$

For the mixtures of TPGS-PEG 400-water, $\chi_{12}$, $\chi_{23}$, and $\chi_{13}$ represent the nonpolar interactions between water and PEG 400 ( $\chi_{\text {PEG 400-water }}$ ), PEG 400 and TPGS ( $\chi_{\text {TPGS-PEG } 400}$ ), and water and TPGS ( $\left.\chi_{\text {TPGS-water }}\right) ; \chi_{12}=\chi_{13} \geq 0$, based on the original $\mathrm{F}-\mathrm{H}$ theory and $\chi_{23} \cong 0$ (mixing of homologous polymers) from literature. ${ }^{36,37}$ Therefore, these interactions do not contribute to mixing favorably. Comparing Eq. 6 with Eq. 5, the addition of water can increase the entropy of the system because water is a small molecule (see Table 2). More importantly, the introduction of water into TPGS-PEG $400 \mathrm{mix}$ tures also introduces two additional hydrogen bonding interactions: $\Delta \mathrm{G}_{\mathrm{HTPGS}-\text { water }}$ and $\Delta \mathrm{G}_{\mathrm{HPEG}} 400-$ water . As shown in literature, the mixing of PEG 400 with water is typically exothermic and the heat of mixing per gram of water at room temperature for $\mathrm{PEG}$ 400 can vary from a few joules (negative) to a few thousands joules (negative) depending on the polymer concentration. ${ }^{12}$ Similarly, the mixing of PEG 1000 , the hydrophilic portion of TPGS, with water is also typically exothermic and its value depends on both temperature and concentration. As shown in Figure 4, with the presence of water $(\mathrm{w} / \mathrm{w})$ in the mixtures of TPGS-PEG $400-$ water from $5 \%$ to $20 \%, T_{\mathrm{c}}$ was consistently reduced, particularly at a TPGS concentration less than $35 \%$. To explain the contribution of water to the decrease in $T_{\mathrm{c}}$, both the entropy of mixing (combinatorial term) and the resultant free energy change due to hydrogen bonding needs to be evaluated. With an introduction of a small amount of water, an small increase in the entropy of the system is shown (see Table 2 , for instance, the entropy term is $\sim 26 \mathrm{~J} / \mathrm{cm}^{3}$ for $5 \%$ water $/ 75 \%$ PEG $400 / 20 \%$ RTPGS as compared with $2.5 \mathrm{~J} / \mathrm{cm}^{3}$ for PEG 400/TPGS system at 80\% PEG 400 and 20\% TPGS), and the contribution of the hydrogen bonding interactions between TPGS and water $\left(\Delta \mathrm{G}_{\text {HTPGS-water }}\right)$ as well as PEG 400 and water $\left(\Delta \mathrm{G}_{\text {HPEG }} 400\right.$-water $)$ is also very small due to small quantity of water and, therefore, the impact of water on the overall free energy and the phase behavior of TPGS-PEG 400 mixtures is very limited. By increasing the water concentration $(10 \%$ and $15 \%)$ in the mixtures of TPGS-PEG 400-water, the contribution of water to both entropy (see Table 2) and hydrogen bonding interaction becomes significant. Experimentally it was seen that first the cloud point temperature of the system was reduced with increasing water concentration due to a free energy change. Secondly, the interaction between water and PEG 400/TPGS became so dominant that $T_{\mathrm{c}}$ remained constant in most of the TPGS concentration range, suggesting that entropy effect has diminished. In particular, when the water concentration was increased to $20 \%$, the contribution from the PEG 400-water/TPGS-water

Table 2. The Calculated Combinatorial Entropy (in Terms of $R T / V_{0}$ ) of PEG $400-$ TPGS-Water Ternary System

\begin{tabular}{lccc}
\hline $\begin{array}{l}\text { Percentage } \\
\text { of TPGS }\end{array}$ & $\begin{array}{c}\text { Percentage } \\
\text { of Water }\end{array}$ & $\begin{array}{c}\text { Percentage of } \\
\text { PEG 400 }\end{array}$ & $\begin{array}{c}\text { Calculated Entropy } \\
\left(R T / V_{0}\right)\left(\mathrm{J} / \mathrm{cm}^{3}\right)^{a}\end{array}$ \\
\hline 20 & 5 & 75 & -0.191 \\
20 & 10 & 70 & -0.275 \\
20 & 15 & 65 & -0.334 \\
20 & 20 & 60 & -0.374 \\
20 & 25 & 55 & -0.402 \\
\hline
\end{tabular}

${ }^{a}\left(R T / V_{0}\right)$ is $138 \mathrm{~J} / \mathrm{cm}^{3}$ at $298 \mathrm{~K}$. 
Table 3. The Calculated Combinatorial Entropy (in Terms of $R T / V_{0}$ ) of PEG 1450-TPGS Binary System

\begin{tabular}{lccc}
\hline $\begin{array}{l}\text { Percentage } \\
\text { of TPGS }\end{array}$ & $\begin{array}{c}\text { Percentage of } \\
\text { PEG 1450 }\end{array}$ & $\begin{array}{c}\text { Calculated Entropy } \\
\left(R T / V_{0}\right)\left(\mathrm{J} / \mathrm{cm}^{3}\right)^{a}\end{array}$ & Comments \\
\hline 10 & 90 & -0.0130 & Early part of the curve \\
20 & 80 & -0.0196 & No significant decrease of cloud point \\
30 & 70 & -0.0235 & \\
40 & 60 & -0.0255 & \\
50 & 50 & -0.0259 & Cloud point starts to decrease \\
60 & 40 & -0.0248 & \\
70 & 30 & -0.0221 & \\
80 & 20 & -0.0178 & \\
90 & 10 & -0.0113 & \\
\hline
\end{tabular}

${ }^{a}\left(R T / V_{0}\right)$ is $68 \mathrm{~J} / \mathrm{cm}^{3}$ at $298 \mathrm{~K}$ if a density value of $1.2 \mathrm{~g} / \mathrm{cm}^{3}$ is used for PEG 1000/PEG 1450.

interactions ( $\left.\chi_{\text {TPGS-water }}\right)$ was so great that gel formation was observed. It is also possible that other phase structure formed at this concentration because both PEG 400 and TPGS can form organized structures as their concentration increases. ${ }^{38,39}$ However, we are only focusing on the practical aspects of their phase behavior.

A similar analysis can be used to evaluate the impact of ethanol on the phase behavior of the mixtures of TPGS-PEG 400. As shown in Table 2, the entropy change of the system when ethanol is added is the same as that with added water and, therefore, the effect of combinatorial entropy on free energy should be same for both systems. As shown in Figure 5, ethanol was not very effective in reducing $T_{\mathrm{c}}$ as compared with water. The extent of $T_{\mathrm{c}}$ reduction was only about $5{ }^{\circ} \mathrm{C}$ even when $25 \%$ ethanol was added. In addition, $T_{\mathrm{c}}$ always increased with increasing TPGS concentration. This suggests that the hydrogen bonding interaction between ethanol and TPGS as well as between PEG 400 and ethanol is very weak or does not exist. This is supported by the fact that mixing of PEG with ethanol is not exothermic and, in fact, it is reported that mixing of PEG 400/200 mixture with ethanol can yield excess molar enthalpy of $1034 \mathrm{~J}$ due to breaking up of the strong hydrogen bonding among the alcohol molecules. ${ }^{13,14}$ Therefore, $T_{\mathrm{c}}$ reduction with addition of ethanol might be mainly due to the contribution of combinatorial entropy.

\section{TPGS-PEG 1450 System}

Regarding the binary mixture of TPGS-PEG 1450, the entropic contribution to the free energy of mixing, $\frac{R T}{V_{0}}\left(\frac{\phi_{1} \ln \phi_{1}}{23}+\frac{\phi_{2} \ln \phi_{2}}{32}\right)$ according to Equation 1, is very small as shown in Table 3. This is because PEG 1450 has a degree of polymerization of 32 and TPGS (the PEG 1000 portion) has a degree of polymerization of 23. Based on literature data, ${ }^{36,37}$ TPGS and PEG 1450 have very little nonpolar interaction and therefore, $\chi_{\text {TPGS-PEG } 1450}$ is fairly small and can be treated as zero. As shown in Figure 6, $T_{\mathrm{c}}$, which remains almost constant in most of the concentration range of PEG 1450, started to decrease significantly only when

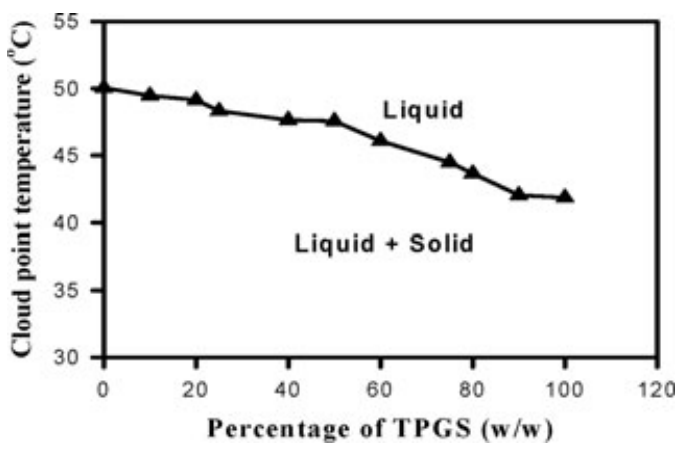

Figure 14. Phase diagram of TPGS-PEG 1450 based on melting of TPGS-PEG 1450 mixtures (w/w).

the TPGS concentration reached about $65 \%$, indicating that there is a strong interaction between PEG 1450 and TPGS possibly due to hydrogen bonding at a high TPGS concentration ( $>65 \%)$. On the basis of DSC thermograms shown in Figure 9, it appears that TPGS and PEG 1450 formed a single phase when the TPGS concentration was greater than $75 \%$. This is again an indication that there might be a strong interaction between TPGS and PEG 1450 at this concentration of TPGS. On the basis of the DSC thermograms shown in Figure 10, it can be concluded that the presence of TPGS in the TPGS-PEG $1450 \mathrm{mix}$ tures decreased the onset temperature of crystallization. In Figure 14, the DSC data originally shown in Figure 9 was replotted, in which the melting point of the solid phase of TPGS-PEG 1450 and the temperature at which the last portion of the solid disappeared was plotted as a function of TPGS concentration. As shown in Figure 14, a continuous decrease in the melting point with TPGS is observed, which can be modeled using a melting point depression equation for macromolecules:

$$
\Delta T=-\frac{R T T_{\mathrm{M}}}{\Delta H_{\mathrm{f}}}\left[\ln \left(1-\phi_{1}\right)+(1-x)\left(\phi_{1}\right)+\chi x\left(\phi_{1}\right)^{2}\right]
$$

where $T_{\mathrm{M}}$ and $\Delta H_{\mathrm{f}}$ are the melting temperature and the heat of fusion of PEG 1450, and $\phi_{1}, x$, and $\chi$ are the volume fraction of TPGS, the volume ratio 


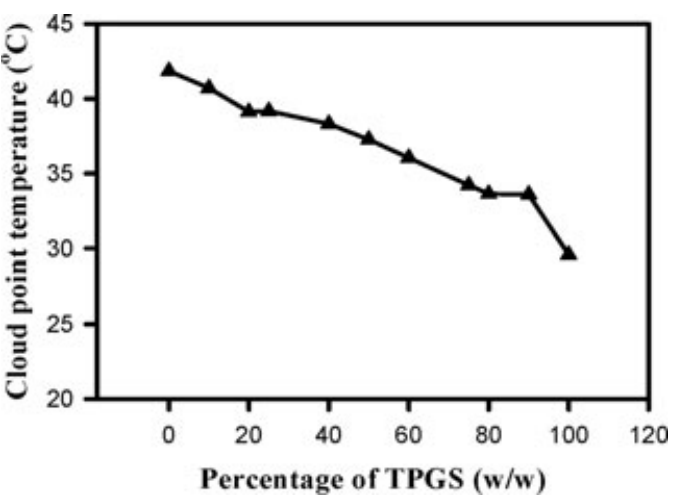

Figure 15. Phase diagram of TPGS-PEG 1450 based on crystallization of TPGS-PEG 1450 mixtures (w/w).

of PEG 1450 over TPGS, and the F-H interaction parameter between TPGS and PEG $1450,{ }^{40,41}$ respectively. On the basis of Eq. 7, there are three parameters affecting the melting point: the volume ratio, the $\mathrm{F}-\mathrm{H}$ interaction parameter, and the volume fraction. A small molecule can significantly affect the melting point of a big molecule (large $x$ ). In the case of TPGS, it always reduces the PEG 1450 melting point. Because the volume ratio of PEG 1450 to TPGS is not very big, it is expected that the interaction would play a role in the TPGS-PEG 1450 phase diagram (melting). As seen in Figure 14, TPGS only moderately influences the melting point of PEG 1450. The onset temperature from the crystallization curve in Figure 10 is plotted as a function of TPGS concentration in Figure 15, which shows a similar trend as that of the melting curve, except that there is a temperature shift due to the difference between the onset temperature for melting and the one for crystal formation.

\section{TPGS-PEG-Ibuprofen}

Similarly, the F-H theory for a ternary system can be applied to the mixtures of TPGS-PEG-ibuprofen (see Eq. 6). On the basis of Eq. 6, the contribution of ibuprofen to the entropy of mixing should be similar to that of water or ethanol because ibuprofen is also a small molecule. As shown in Figures 12 and 13 , ibuprofen can significantly impact the $T_{\mathrm{c}}$ of the TPGS-PEG 400 and TPGS-PEG 1450 mixtures, indicating a strong interaction between ibuprofen and the other two components. Therefore, the reduction of $T_{\mathrm{c}}$ is probably due to some specific interactions in addition to the effect of melting point depression as indicated in Eq. 7. However, the type of specific interaction existing for these mixtures cannot currently be identified, although it is speculated to be hydrogen bonding based on the structure of ibuprofen. A further investigation is needed to clarify this matter.

\section{Implications on Formulation Development}

In practice, $T_{\mathrm{c}}$, which is an upper critical solution temperature for the systems reported in this paper, is a critical parameter to consider from storage point and operational point of view. Experimentally, cloud points are best determined by light scattering, neutron scattering, and other spectroscopic methods. However, this is not practical in most pharmaceutical companies. Therefore, cloud points are likely to be observed with naked eyes as was observed by Shultz and Flory ${ }^{18}$ 1950. In this case, it is difficult to exactly determine the temperature of phase separation because often the cloud points are discerned after significant phase growth occurs. As reported in the literature, cloud point values are also affected by the rate of cooling and kinetics of heat transfer. ${ }^{42}$ Nevertheless, it is still a useful tool to guide formulation development, particularly when a storage condition for a formulation is in question. For the current formulations consisting of TPGS and PEG 400, the ratio of TPGS to PEG 400 will vary depending on the physical, chemical, and biological properties of compounds. A typical range of concentration for TPGS is between $5 \%(\mathrm{w} / \mathrm{w})$ and $15 \%(\mathrm{w} / \mathrm{w})$. As shown in Figure 2, in this concentration range, the cloud point temperature of TPGS-PEG 400 mixtures could vary from $22^{\circ} \mathrm{C}$ to $25^{\circ} \mathrm{C}$ without considering the impact of API. Therefore, a formulation with $T_{\mathrm{c}}$ between $22^{\circ} \mathrm{C}$ and $25^{\circ} \mathrm{C}$ needs to be stored above $25^{\circ} \mathrm{C}$ to avoid phase separation. As seen in Figure 4, the presence of a specified amount of water lowers the $T_{\mathrm{c}}$, allowing the formulation to be stored at room temperature. In the case of formulations containing ethanol, $T_{\mathrm{c}}$ is above $20^{\circ} \mathrm{C}$ when the TPGS concentration is $15 \%$, without considering the influence of API. Therefore, these formulations need to be maintained above $20^{\circ} \mathrm{C}$ to avoid physical stability issues. In the case of ibuprofen formulations, the $T_{\mathrm{c}}$ was lowered by Ibuprofen. Therefore, formulations containing ibuprofen would be maintained in their liquid state at room temperature.

For formulations involving TPGS and PEG 1450, the phase structure of the vehicles in the formulations needs to be considered as the TPGS concentration increases. Below 75\% there are two phases and above $75 \%$, only single phase forms. Without considering the impact of API, formulations with a high TPGS concentration have a low melting temperature, which facilitates the dissolution of a vehicle in vivo. In addition, increasing amounts of TPGS may, in some instances, stabilize the API. For hard gelatin capsule formulations using PEG 1450/TPGS, melting and crystallization temperatures are more practically useful as compared with cloud point because they might be related to formulation performance and its stability related to manufacturing. In the case of ibuprofen formulations, $T_{\mathrm{c}}$ was reduced. It is suspected that these 
formulations may liquefy at a lower temperature, which may impact the stability and other aspects of these formulations. In general, API can impact the phase behavior of a formulation significantly. In cases where $T_{\mathrm{c}}$ is reduced by API, it has a beneficial impact on liquid formulations from a physical stability point of view. However, for semisolid formulations, it has a negative impact in terms of chemical stability, in that a higher $T_{\mathrm{c}}$ will enhance the stability of the formulations. It has an opposite effect when API increases the $T_{\mathrm{c}}$ of the formulations.

\section{CONCLUSIONS}

On the basis of the phase diagram of TPGS-PEG 400 , it was found that TPGS increased the cloud point of PEG 400, suggesting that any PEG 400 formulation containing TPGS may have the potential for precipitation of TPGS during storage. Both water and ethanol, according to the phase diagrams of TPGS-PEG 400-water and TPGS-PEG 400-ethanol, lowered the cloud point of the TPGS-PEG 400 system. Water was more efficient than ethanol in lowering the cloud point of the system, presumably due to the fact that water/TPGS and water/PEG 400 have strong hydrogen bonding interaction. ${ }^{43}$ The effect of API on the phase behavior of TPGS-PEG 400 was evaluated by using ibuprofen as a model compound. It was observed that ibuprofen reduced the $T_{\mathrm{c}}$ of TPGS-PEG 400 significantly. As indicated in the TPGS-PEG 1450 and TPGS-PEG 1450-ibuprofen phase diagrams, the cloud points of these mixtures were reduced by both TPGS and ibuprofen. In addition, the presence of TPGS in PEG 1450 formulations systematically depressed the melting point of PEG 1450. TPGS and PEG 1450 formed a single phase when the TPGS concentration was above $75 \%$, as indicated by the DSC results. However, XRPD diffractograms did not show any structural changes because TPGS and PEG 1450 have similar XRPD patterns. FT-Raman data indicated that, in this case, the molecular interaction between TPGS chains might be interrupted.

\section{ACKNOWLEDGMENTS}

The authors thank Ms. Anisha Patel (Bristol-Myers Squibb) for obtaining powder X-ray diffractogram, Dr. Dimuthu Jayawickrama (Bristol-Myers Squibb) for obtaining FT-Raman spectra, and Prof. Zografi (School of Pharmacy, University of Wisconsin at Madison) for comments. They also thank the management of Drug Product Science \& Technology for its support, and Doris Chiappetta (Boehringer Ingelheim Pharmaceuticals, Inc.) for her critical review of the manuscript.

\section{REFERENCES}

1. Comer JEA. 2003. High-throughput measurement of $\log \mathrm{D}$ and $\mathrm{pK}_{\mathrm{a}}$. In Drug bioavailability: Estimation of solubility, permeability, absorption and bioavailability; Van de Waterbeemd $\mathrm{H}$, Lennernas H, Artursson P, Eds. Weinheim, Germany: WileyVCH, pp 21-45.

2. Kerns EH, Di L. 2008. Drug-like properties: Concepts, structure design and methods from ADME to toxicity optimization. San Diego, CA: Academic Press, pp 6-16.

3. Amidon GL, Lenernas H, Shah VP, Crison JR. 1995. A theoretical basis for a biopharmaceutical classification, the correlation of in vitro drug product dissolution and in vivo bioavailability. Pharm Res 12:413-420.

4. Grove M, Mullertz A. 2007. Liquid self-microemulsifying drug delivery systems. In Oral lipid-based formulations: Enhancing the bioavailability of poorly water-soluble drugs; Hauss D, Ed. New York: Infoma HealthCare, pp 107-127.

5. Strickley RG. 2004. Solubilizing excipients in oral and in jectable formulations. Pharm Res 21:201-230.

6. Palepu NR, Bulusu BT. 2008. Solubilized formulation of docetaxel without tween 80, Patent US20080319048A1.

7. Rubinfeld J, Gore AY, Joshi R, Shrotriya, R. 2000. Formulation for paclitaxel. Patent US006136846.

8. Yu L, Bridgers A, Polli J, Vickers A, Long S, Roy, A, Winnike R, Coffin M. 1999. Vitamin E-TPGS increases absorption flux of an HIV protease inhibitor by enhancing its solubility and permeability. Pharm Res 16:1812-1817.

9. Abelaira S, Becher MP, Gel JF, Villagra MF, Vidal MNCD. 2008. Self-emulsifying formulation of tipranavir for oral administration, Patent WO2008142090.

10. Sheu MT, Wu AB, Lin KP, Shen CH, Ho HO. 2006. Effect of tocopheryl polyethylene glycol succinate on the percutaneous penetration of minoxidil from water/ethanol/polyethylene glycol 400 solutions. Drug Dev Ind Pharm 32:595-607.

11. Khoo SM, Porter CJH, Charman WN. 2000. The formulation of halofantrine as either non-solubilizing PEG 6000 or solubilizing lipid based solid dispersions: Physical stability and absolute bioavailability assessment. Int J Pharm 205:6578.

12. Wohlfarth C. 2004. CRC handbook of thermodynamic data of aqueous polymer solutions, New York: CRC Press, pp 382, 383, 386.

13. Bigi A, Comeli F. 2005. Excess molar enthalpies of binary mixtures containing ethylene glycols or poly(ethylene glycols) + ethyl alcohol at $308.15 \mathrm{~K}$ and atmospheric pressure. Thermochim Acta 430:191-195.

14. Lakhanpal ML, Sharma SC, Krishan B, Parashar RN. 1976. Enthalpies of mixing of polyoxyethylene glycols in benzene, carbon tetrachloride, methyl alcohol \& ethyl alcohol. Indian J Chem 14:642-644.

15. Sjöberg A, Karlström G. 1989. Temperature dependence of the phase equilibria for the system poly (ethylene glycol)/dextran/ water. A theoretical and experimental study. Macromolecules 22:1325-1330.

16. Jung JG, Bae YC. 2010. Liquid-liquid equilibria of polymer solutions: Flory-Huggins with specific interaction. J Polym Sci B Polym Phys 48:162-167.

17. Karlström G. 1985. A new model for upper and lower critical solution temperature in poly(ethylene oxide) solutions. J Phys Chem 89:4962-4964.

18. Shultz AR, Flory PJ. 1952. Phase equilibria in polymersolvents systems. J Am Chem Soc 74:4760-4767.

19. Kamide K. 1990. Thermodynamics of polymer solutions: Phase equilibria and critical phenomena. Amsterdam, The Netherland: Elsevier, pp 10-233 .

20. Shirataki H, Kamide K. 1993. Phase equilibria of quasiternary systems consisting of multicomponent polymers 1 
and 2 in a single solvent II. Cloud point curve. Polym Int 32:265-273.

21. Saraiva A, Persson O, Fredenslund A. 1993. An experimental investigation of cloud-point curves for the poly(ethylene glycole)/water system at varying molecular weight distributions. Fluid Phase Equilib 91:291-311.

22. Lin-Vien D, Colthup NB, Fateley WG, Grasselli JG. 1991. The handbook of infrared and raman characteristic frequencies of organic molecules. San Diego: Academic Press, pp 9-28 .

23. Blaha JJ, Rosasco GJ. 1981. Raman microprobe characterization of urea: n-Paraffin inclusion compounds. J Raman Spectrosc 11:75-80.

24. Matsuura H, Fukuhara K. 1986. Vibrational spectroscopic studies on conformation of poly(oxyethylene). II. Conformation-spectrum correlations. J Polym Sci B Polym Phys 24:1383-1400.

25. Flory PJ. 1956. Principles of polymer chemistry. Ithaca, NY: Cornell University press, pp 495-540.

26. Coleman MM, Graf JF, Painter PC. 1991. Specific interactions and the miscibility of polymer blends. Lancaster, Pennsylvania: Technomic Publishing Company, Inc., pp 49.

27. Kamide K, Dobashi T. 2000. Physical chemistry of polymer solution. Amsterdam, The Netherlands: Elsevier, pp 50 -93.

28. Klenin VJ. 1999. Thermodynamics of systems containing flexible-chain polymers. Amsterdam, The Netherlands: Elsevier, pp 253-508.

29. Koningsveld R, Stockmayer WH, Nies E. 2001. Polymer phase diagrams: A textbook. New York: Oxford University Press, pp 117-136.

30. Painter PC, Park Y, Coleman MM. 1989. Thermodynamics of hydrogen bonding in polymer blends. 1 . The application of association models. Macromolecules 22:570-579.

31. Painter PC, Park Y, Coleman MM. 1988. Hydrogen bonding in polymer blends. 2. Theory. Macromolecules 21:66-72.
32. Hanke E, Schulz U, Kaatze U. 2007. Molecular interactions in poly(ethylene glycol)-water mixtures at various temperatures: Density and isentropic compressibility study. Chem Phys Chem 8:553-560.

33. Haynes CA, Beynon RA, King RS, Blanch HW, Prausnitz JM. 1989. Thermodynamic properties of aqueous polymer solutions: Poly(ethylene glycol)/dextran. J Phys Chem 93:5612-5617.

34. Hildebrand JH, Scott RL. 1964. The solubility of nonelectrolytes. New York: Dover Publications Inc., pp 198-209.

35. Tompa H. 1956. Polymer solutions. New York: Academic Press, pp 174-232.

36. Lipatov YS, Nesterov AE. 1997. Thermodynamics of polymer blends. Lancaster, Pennsylvania: Technomic Publication Inc., pp 81-226.

37. Lipatov YS, Nesterov AE. 1997. Thermodynamics of polymer blends. Lancaster, Pennsylvania: Technomic Publication Inc. pp 114-118.

38. Derkaoui N, Said S, Grohens Y, Olier R, Privat M. 2007. PEG 400 novel phase description in water. J Colloid Interface Sci 305:330-338.

39. Wu S, Hopkins WK. 1999. Characteristics of D- $\alpha$-tocopheryl PEG 1000 succinate for applications as an absorption enhancer in drug delivery systems. Pharm Technol 23:52-68.

40. Wunderlich B. 2005. Thermal analysis of polymeric materials. New York: Springer, pp 705-777.

41. Smith P, Pennings AJ. 1977. Eutectic solidification of the quasi binary system of isotactic polypropylene and pentaerythrityl tetrabromide. Polym Sci B Polym Phys 15: 523-540.

42. Balsara NP, Rappl TJ, Lefebvre AA. 2004. Does conventional nucleation occur during phase separation in polymer blends? J Polym Sci B Polym Phys 42:1793-1809.

43. Hefford RJ. 1984. Polymer mixing in aqueous solution. Polymer 25:979-984 